\title{
Speed/Torque Estimation and Control of a DC Machine in Four Quadrants Operation Modes
}

\author{
Rakan Khalil Antar \\ Northern Technical University, Technical Engineering College, Mosul, Iraq \\ rakanpe@yahoo.com \\ Received: 15-May-2017 \\ Revised: 13-Sep.-2017 Accepted: 18-Jan.-2018 \\ http://doi.org/10.29194/NJES21020238
}

\begin{abstract}
Transfer function characteristics of a DC machine are used in this paper to estimate speed and torque in four quadrant operation modes. Estimation speed and torque control based on a DC machine transfer function is implemented by measuring the DC chopper instantaneous average output voltage and current. MATLABISIMULINK is used to implement the DC drive circuit in the forward and reverse motoring and regenerative modes, respectively. The DC drive system is simulated at different speed and load torque values in steady state and dynamic operating conditions. Simulation results demonstrate success of the sensorless and PI controller systems, which gives satisfactory agreements between the estimated, actual and reference speed and torque values.
\end{abstract}

Keywords: Sensorless speed and torque control, DC machine, transfer function characteristics, four quadrant operation modes, chopper.

\section{Introduction}

Accurate speed and torque control of a DC machine drive circuit is usually required. In industrial applications, fast and dynamic control of a DC machine drive circuit is very necessary to be developed. This development can be achieved through tracking a high-quality dynamic speed and load torque responses [1]. Also, the performance of power converter circuit and controller techniques has an effect on the DC drive circuit efficiency. Usually proportionalintegral (PI) controller is used to control speed of the DC machines which has ability to keep steady-state error around zero during step change in speed reference value [2]. Adaptive control methods apply to control speed of a DC machine to obtain high speed responses. A fuzzy logic controller presents good speed responses, but selecting the membership functions, rules and scaling factors is considered a difficult matter [3]. On the other hand, artificial neural networks have ability to be trained and adapted with no explanation about what it has learned [2]. In some applications, accurate speed control of a DC machine is required. In this case, speed sensor is usually used to provide speed data which affects on the stability of closed loop system due to characteristics changing. For this reason speed of a DC machine is estimated to avoid speed sensor problems.

In 2013 [4], neuro-fuzzy controller was designed and used to estimate speed of a DC motor under different speed and torque operation conditions based on instantaneous armature current and voltage. The controller employs artificial neural network technique to tune memberships and set rule bases to estimate speed of the DC machine in the four quadrant operation modes. In 2014 [5], sensorless speed control of a DC machine was implemented using artificial neural network with instantaneous armature current and reconstructed output voltage as inputs of the controller in the four quadrant operation modes. The estimated speed and torque of a DC motor in the forward and reverse operation modes based on artificial neural network with instantaneous armature current and voltage as inputs was done in 2016 [6].

In this paper, the sensorless speed and torque control of a separately excited DC motor in the four quadrant operation modes is done depending on DC motor transfer function characteristics and instantaneous output voltage and current to estimate the speed and torque of the DC motor as shown in Figure (1). The designed estimation circuit is simpler than others.

\section{Modeling of Estimation Speed and Torque Circuit}

In order to drive and control speed and torque of a DC motor in the four quadrant operation modes, a DC chopper circuit shown in Figure (1) is used. Speed of the DC motor is controlled by controlling the terminal output voltage of the DC chopper, which dependent on the PWM signal mechanism. The average output DC chopper voltage $\left(V_{\text {ave }}\right)$ is defined as [7]: 


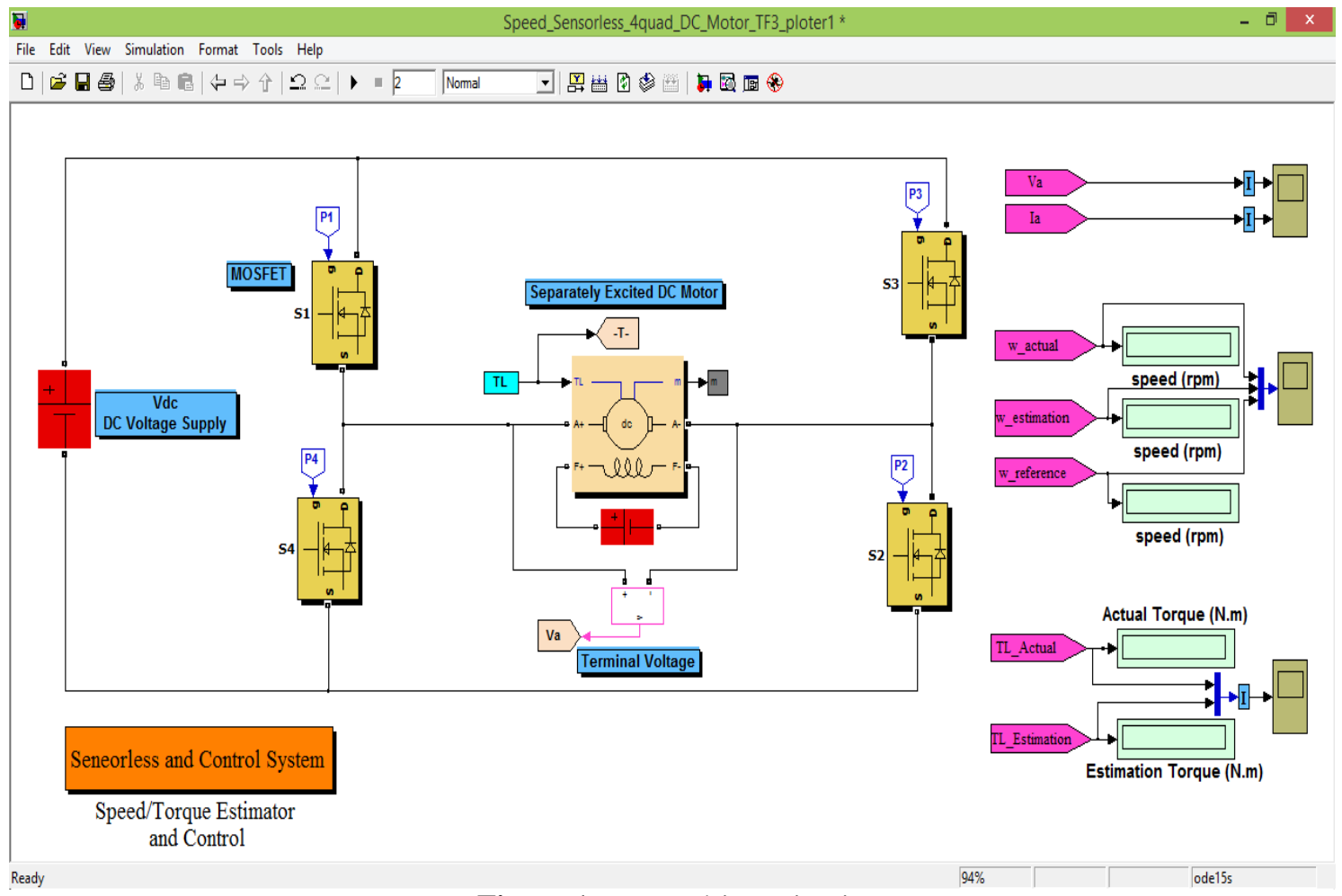

Figure 1: Power drives circuit.

$V_{a v e}=\frac{T_{o n}}{T} \times V_{d c}$

where $T=1 /$ switching frequency and $T_{\text {on }}$ is $\mathrm{ON}$ time period. The speed, current and torques of the DC Machine are estimated using transfer function characteristics of the DC motor as explained in Figure (2). Using the Laplace Transform, the estimated speed $\left(n_{\text {est }}\right)$ current $\left(I_{a-e s t}\right)$ and electrical developed $\left(T_{e-e s t}\right)$ and load $\left(T_{L-e s t}\right)$ torques is given as:-

$I_{a-e s t}(s)=\frac{V_{a v e}(s)-K_{m} \times n_{e s t}(s)}{\left(R_{a}+s L_{a}\right)}$

$T_{e-e s t}(s)=K_{m} \times I_{a-e s t}(s)$

$n_{\text {est }}(s)=\frac{T_{e-e s t}(s)-T_{L-e s t}(s)}{\left(B_{m}+s J\right)}$

$T_{L-e s t}(s)=\left(K_{p}+\frac{K_{i}}{s}\right) \times\left(I_{a}(s)-I_{a-e s t}(s)\right)$

Where $K_{p}, K_{i}, K_{m}, B_{m}, J, R_{a}$ and $L_{a}$ are proportional and integral controller gains, DC machine constant, friction coefficient, moment of inertia, armature resistance and inductance, respectively.

In order to estimate and control speed of the DC motor accurately, load $\left(T_{L}\right)$ and electrical developed $\left(T_{e}\right)$ torques are estimated to get fast speed and torque control responses and agreeable characteristics between the actual, estimated and desired values.

The estimation and control circuit is designed and modeled by MATLAB/SIMULINK in the four quadrant operation modes to evaluate and control speed and torque of the DC machine as shown in Figure (3). The speed and load torque of the DC machine is estimated from the instantaneous armature current and terminal output voltage depending on the DC motor transfer function characteristics. The difference between actual and estimated armature current generates input current error of the PI controller, which is produced estimated load torque. The difference between estimated and reference speeds sent to a PI controller and the output compared with the estimated load torque. The results sent to a different PI controller to get the modulation index value to produce the desired PWM pulses as illustrated in Figure (3). The PI controllers together produce fast response to avoid high current to flow in the DC chopper circuit. As a result, the designed controller makes speed and torque reach steady state as quick as possible during load torque and speed changing.

\section{Four-Quadrant Operation Modes of the DC Drive Circuit}

To explain the four quadrant operation modes of the DC machine, MOSFETs S1 and S2 are controlled and S3 and S4 are switched-off in the 
forward motoring mode. As a result, the DC voltage applies across the DC machine terminals and the armature current $\left(I_{a}\right)$ will rise. But if S1 is switched-off and S2 remained on, the armature current decays through D4. In the forward regenerative mode, MOSFETs S1, S2, S3 and S4 are switched-off and $I_{a}$ flows in the forward direction. Therefore, the machine operates as a generator and energy returns to the DC source during diodes D3 and D4. In the reverse motoring mode, S3 and S4 are controlled and S1 and S2 are switched-off. The $I_{a}$ rises and flows in reverse direction. However if S3 is switched-off and S4 remained on, $I_{a}$ will fall through $\mathrm{S} 4$ and $\mathrm{D} 2$. In the reverse regenerative mode, MOSFETs S1, S2, S3 and $\mathrm{S} 4$ are turned-off and $I_{a}$ will run in the reverse direction and energy returns to the DC source during D1 and D2 [7]. The four quadrant operation modes are illustrated in the Figure (4). The forward and reverse motoring and regenerative operation modes is selected using logic comparators to employ as logical switches according to switching states of the MOSFETs of the DC drive circuit in order to drive gates properly as explained in Figure (3).

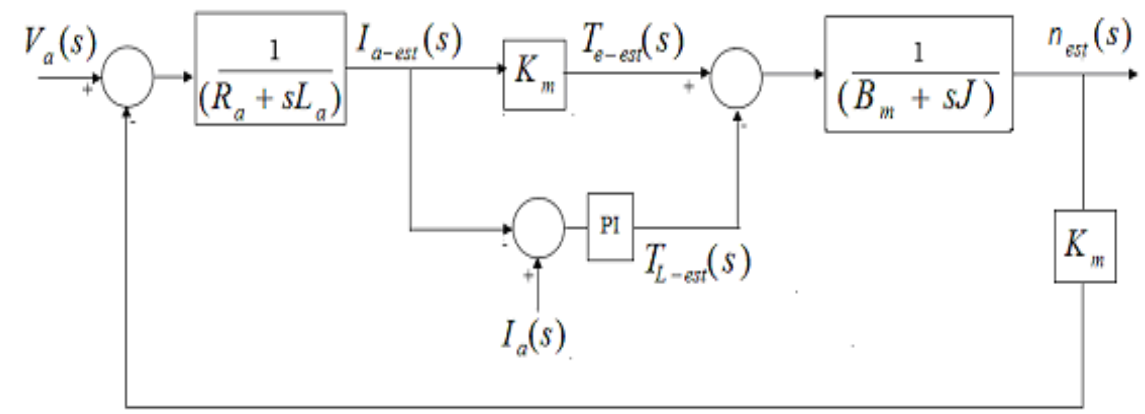

Figure 2: Block diagram of a separately excited DC motor.
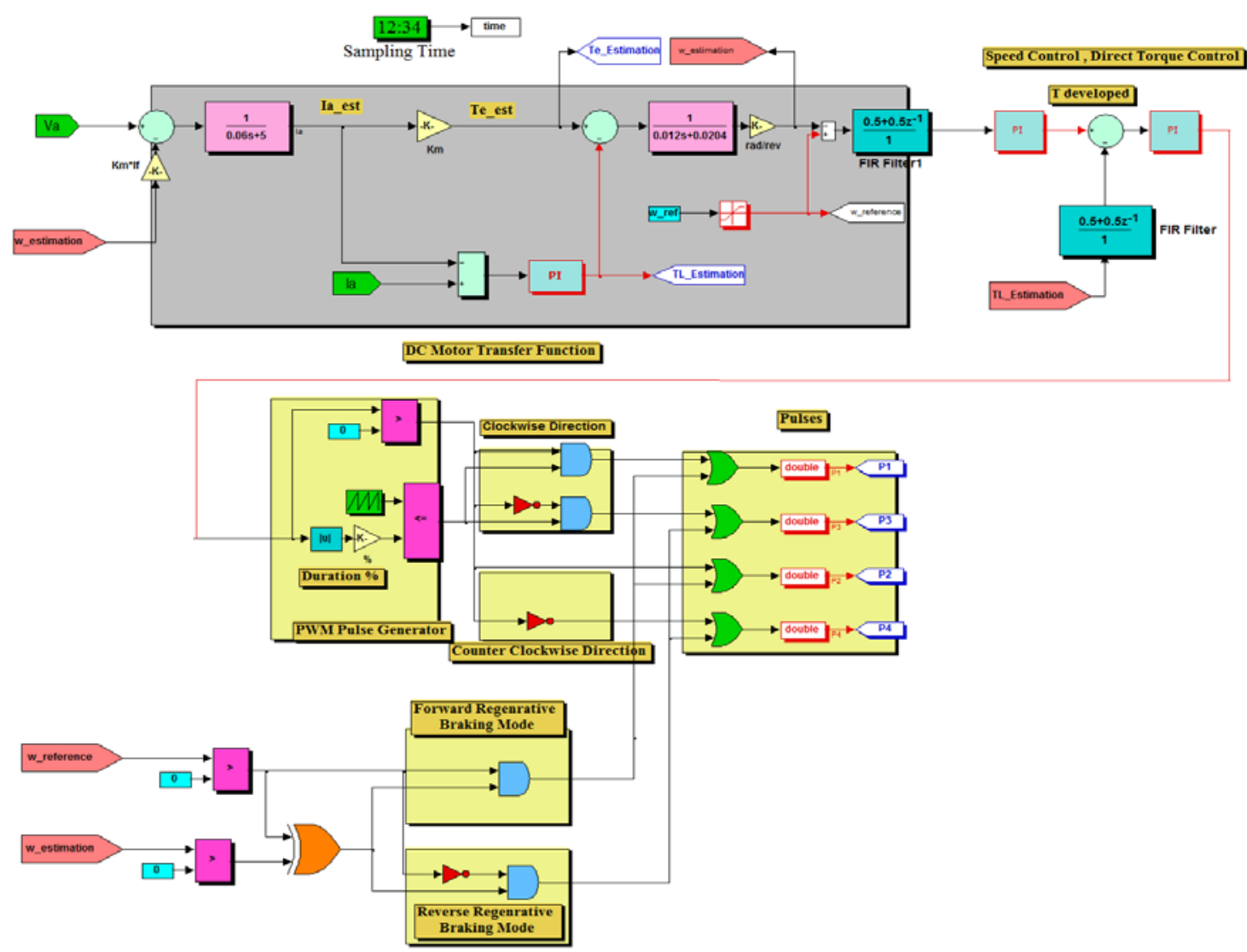

Figure 3: Modeling of the estimated (sensorless) speed and torque controller circuit. 


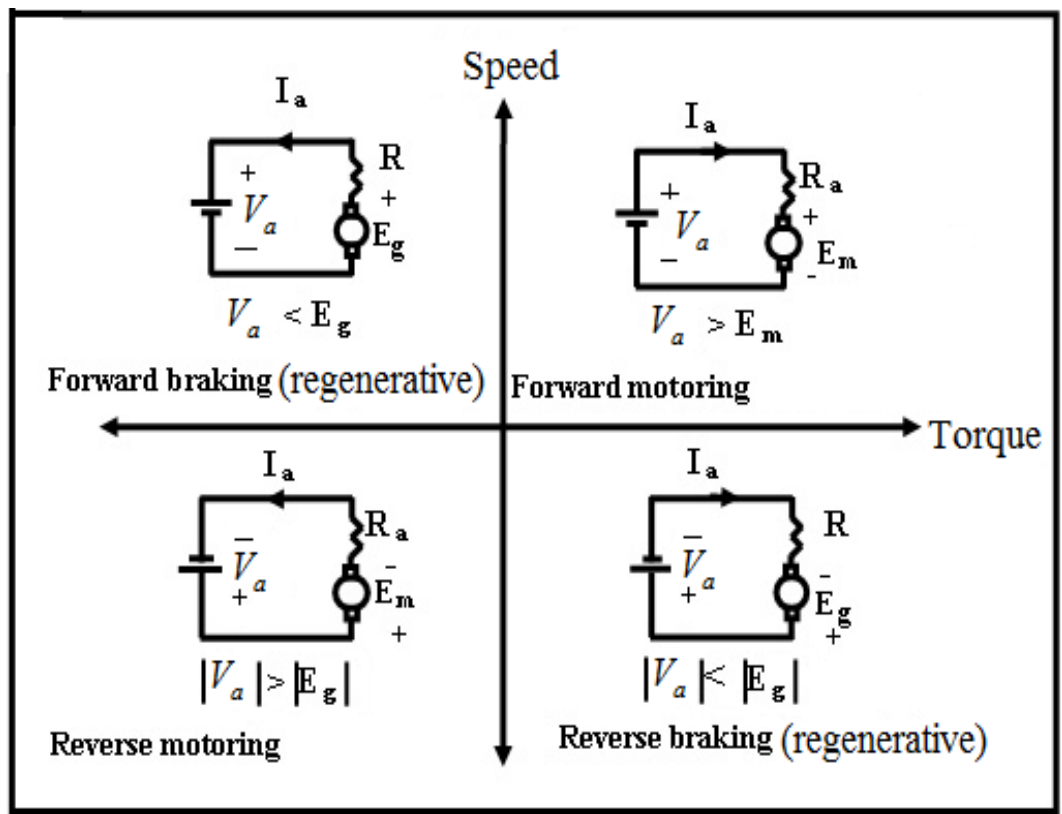

Figure 4: Four quadrants operation characteristics of a DC machine

\section{Simulation Results}

In order to confirm the sensorless speed and torque control strategy as described, simulation by MATLAB/SIMULINK model is carried out on a DC machine drive system whose parameters are given in Appendix. The estimated system is designed under different speed and load torque conditions to run the machine in the four quadrant operation modes as shown in Figure (4).

The speed and load torque responses of the DC machine drive system in the forward and reverse motoring modes individually is shown in Figure (5). The actual and estimated speeds have good responses and get the reference value within 0.5 and 0.52 seconds in the forward and reverse motoring modes, respectively. In order to explain the strength of the estimation and control system in the forward and reverse motoring modes, speed and torque responses with the average output voltage $\left(V_{a v e}\right)$ and current $\left(I_{a}\right)$ waveforms at different speed values are shown in Figure (6) and Figure (7). The $V_{a v e}$ and $I_{a}$ waveforms of the DC drive circuit arrive steady-state response with a certain overshoot due to the controller system nature. The success of the system controller ability to control DC machine in the forward and reverse motoring modes independently at constant speed and different load torques is shown in Figure (8). The speed response continues around the reference value with zero steady state error.

To clarify the strong point of the designed controller to run the DC machine in the forward and reverse motoring modes at the same time, load torque of the DC machine is dynamically changed between $\left(+T_{L}\right)$ and $\left(-T_{L}\right)$ simultaneously as illustrated in Figure (9). The sensorless speed and torque follows the reference values and presents good responses. To get four quadrants operation characteristics of the DC machine drive system, speed and torque is controlled in the forward and reverse regenerative modes as illustrated in Figure (10). This figure explains that the designed system can control and run the DC machine as a generator in the regenerative modes.

The designed estimation and control circuits of the DC machine drive system is active to work in the four quadrants operation modes and give good responses compared with the actual value which confirms the effectiveness of the sensorless speed and torque control system to follow the required speed and torque. 

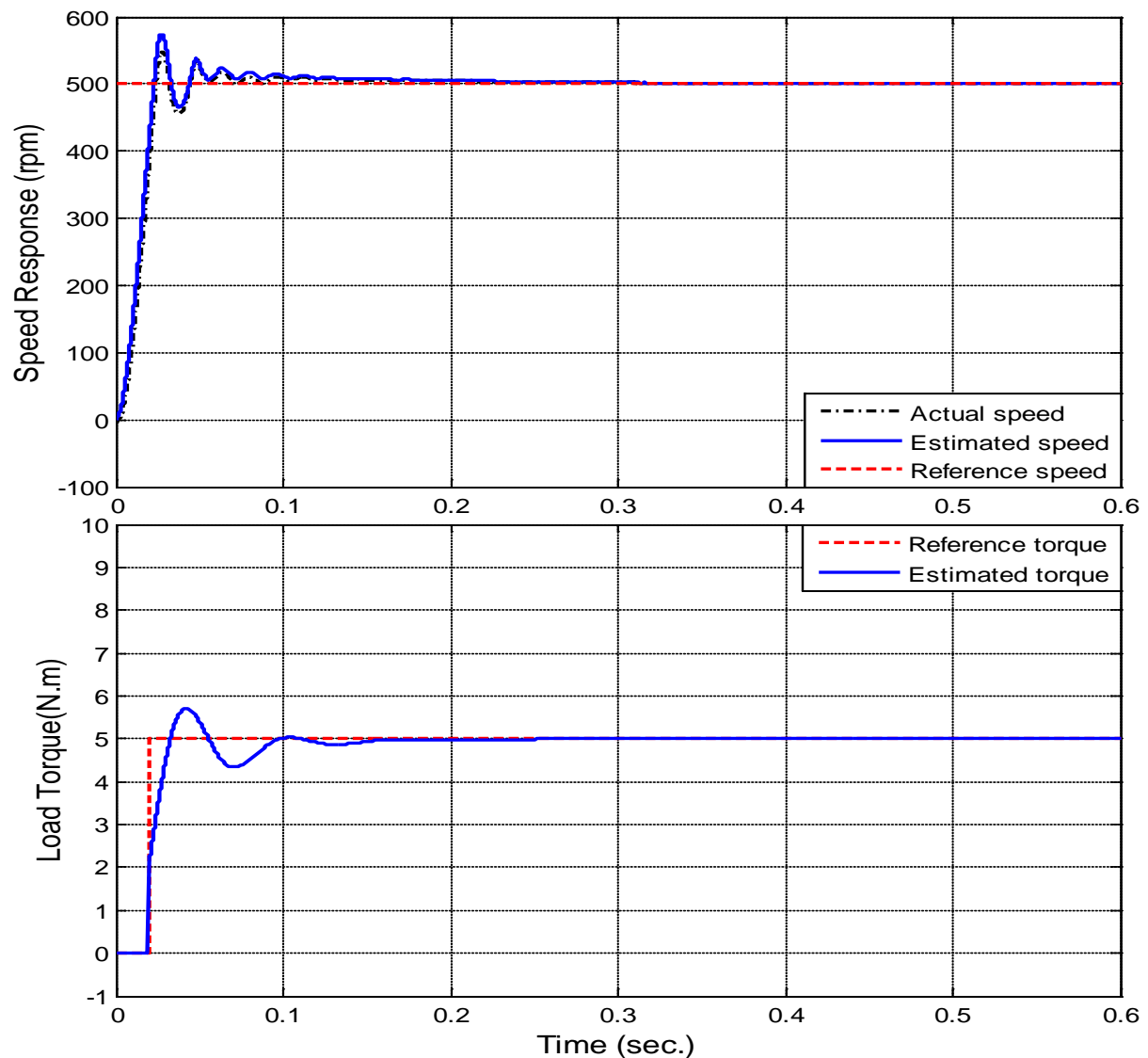

(a)
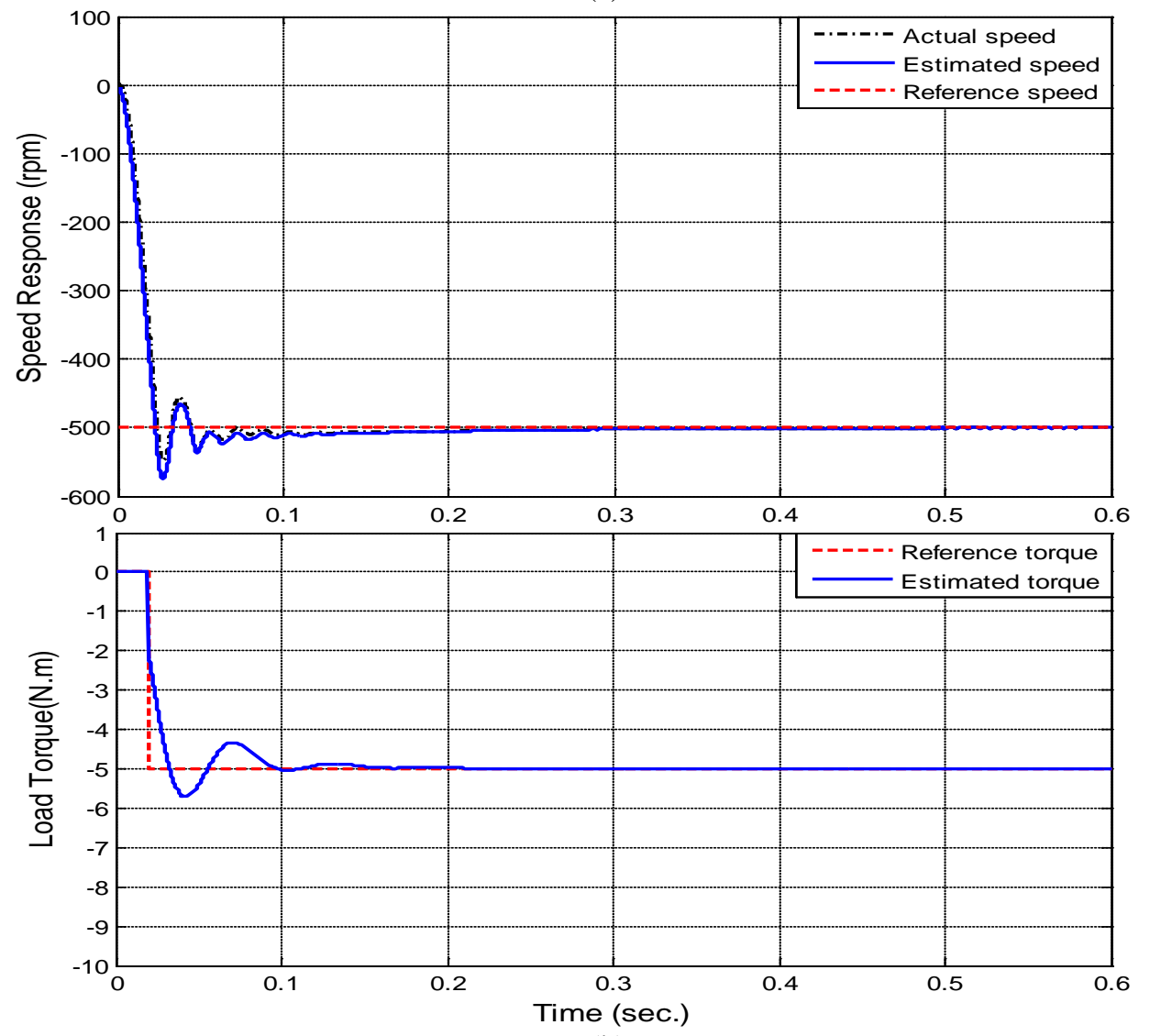

(b)

Figure 5: Speed and torque responses of the DC machine in the (a) forward and (b) reverse motoring modes. 

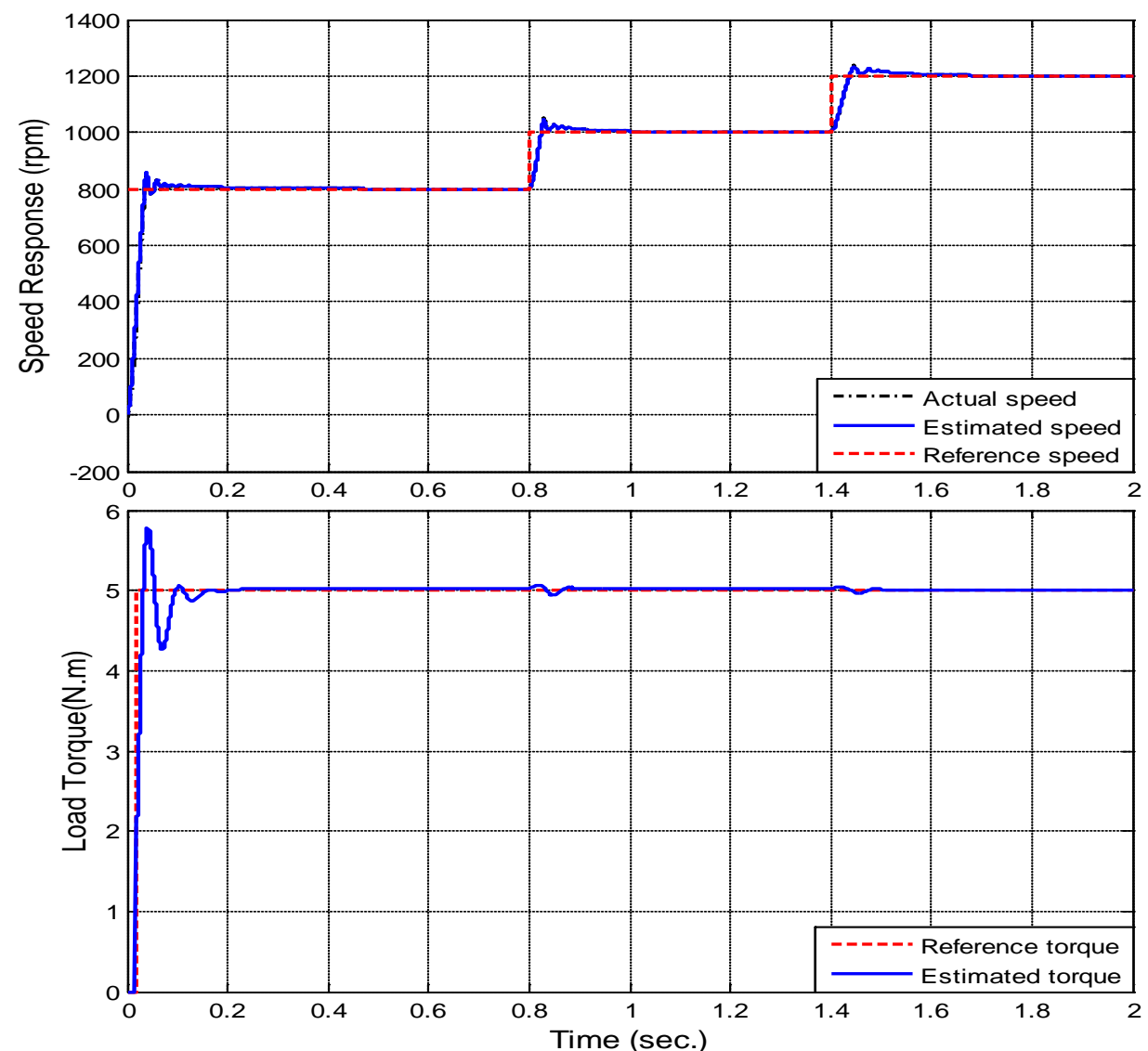

(a)
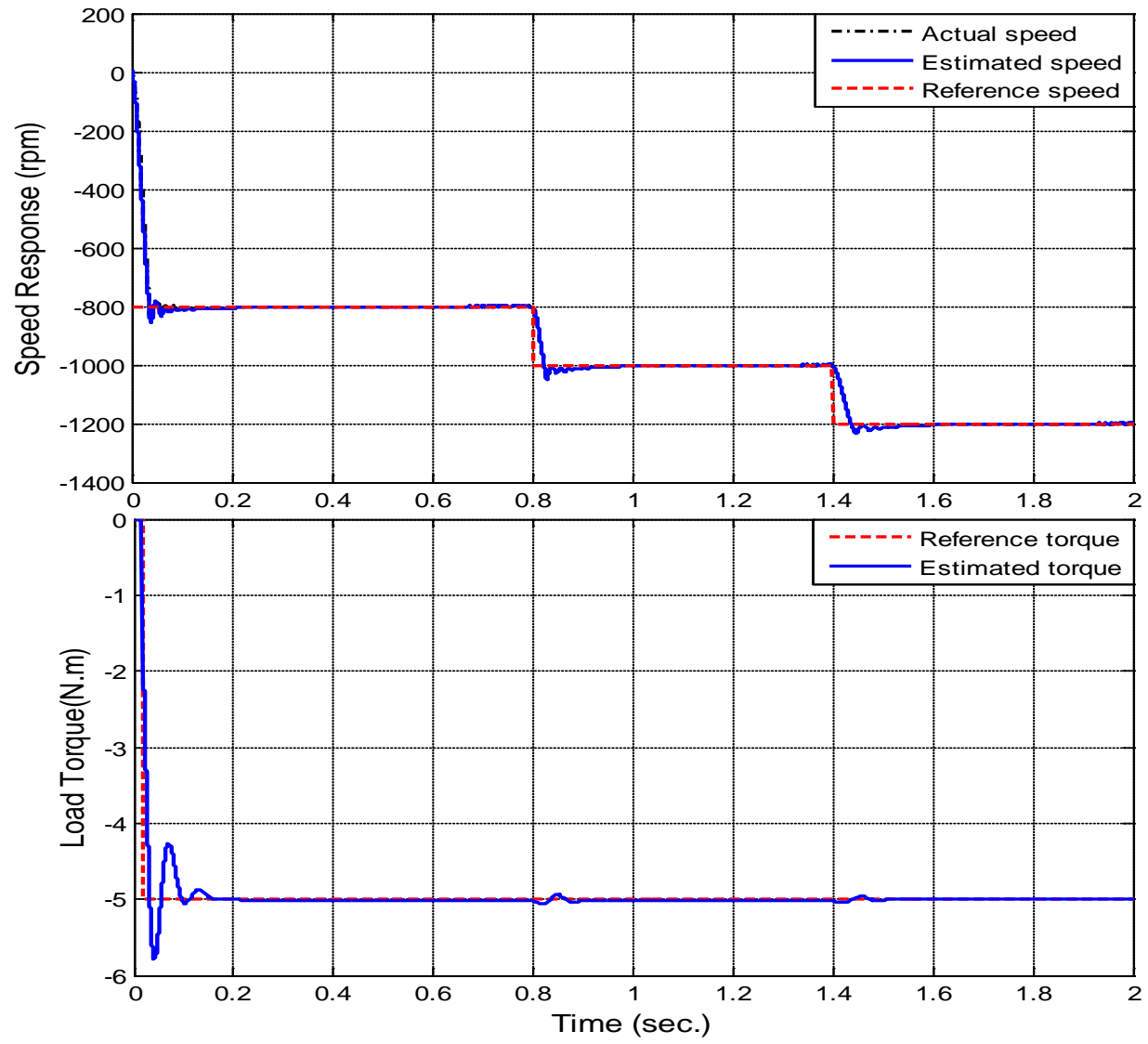

(b)

Figure 6: Speed and torque responses of the DC machine at different speed values in the (a) forward and (b) reverse motoring modes. 

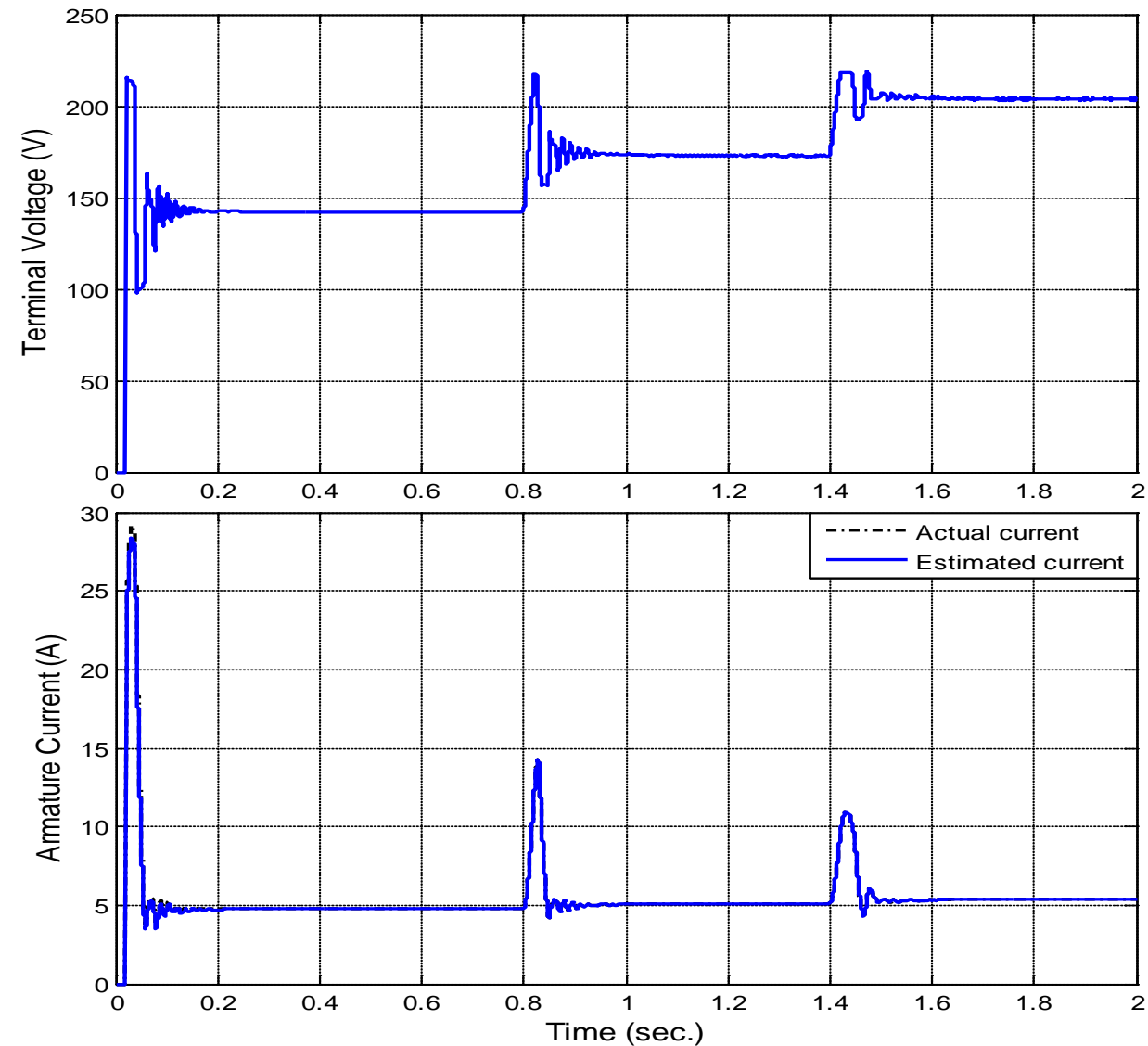

(a)
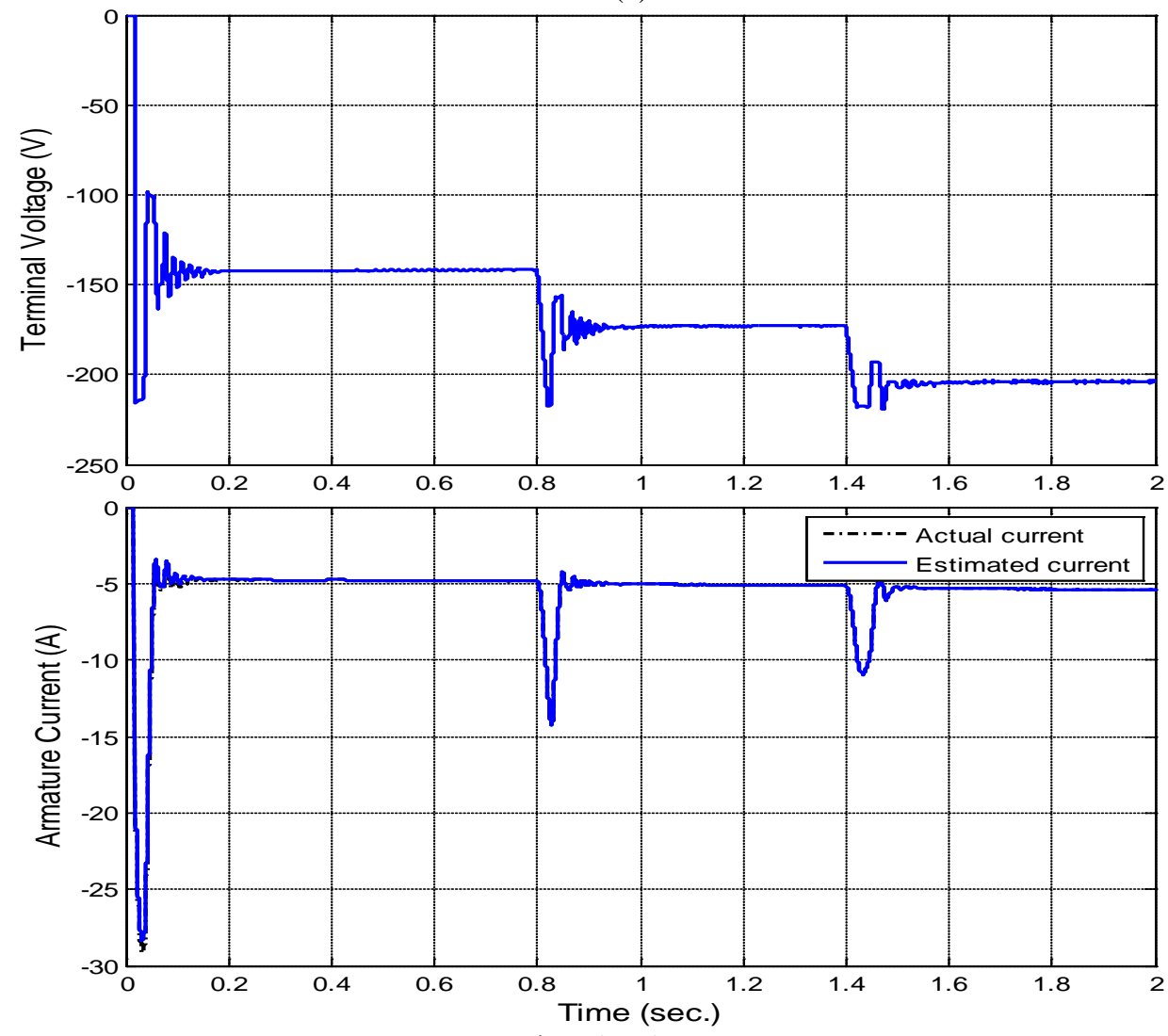

Time (sec.)

(b)

Figure 7: Average terminal output voltage and current responses at different speed values in the (a) forward and (b) reverse motoring modes. 


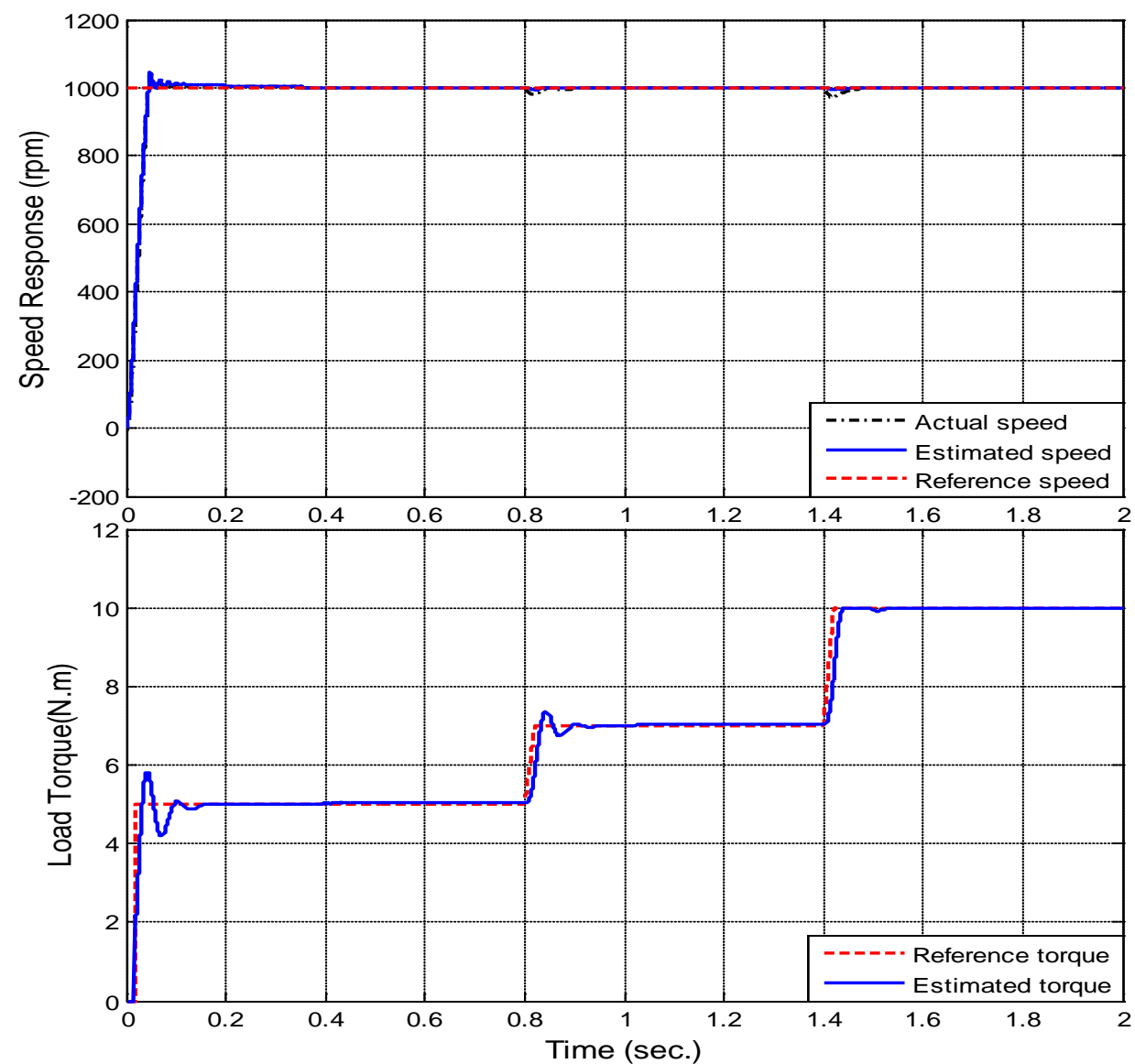

(a)
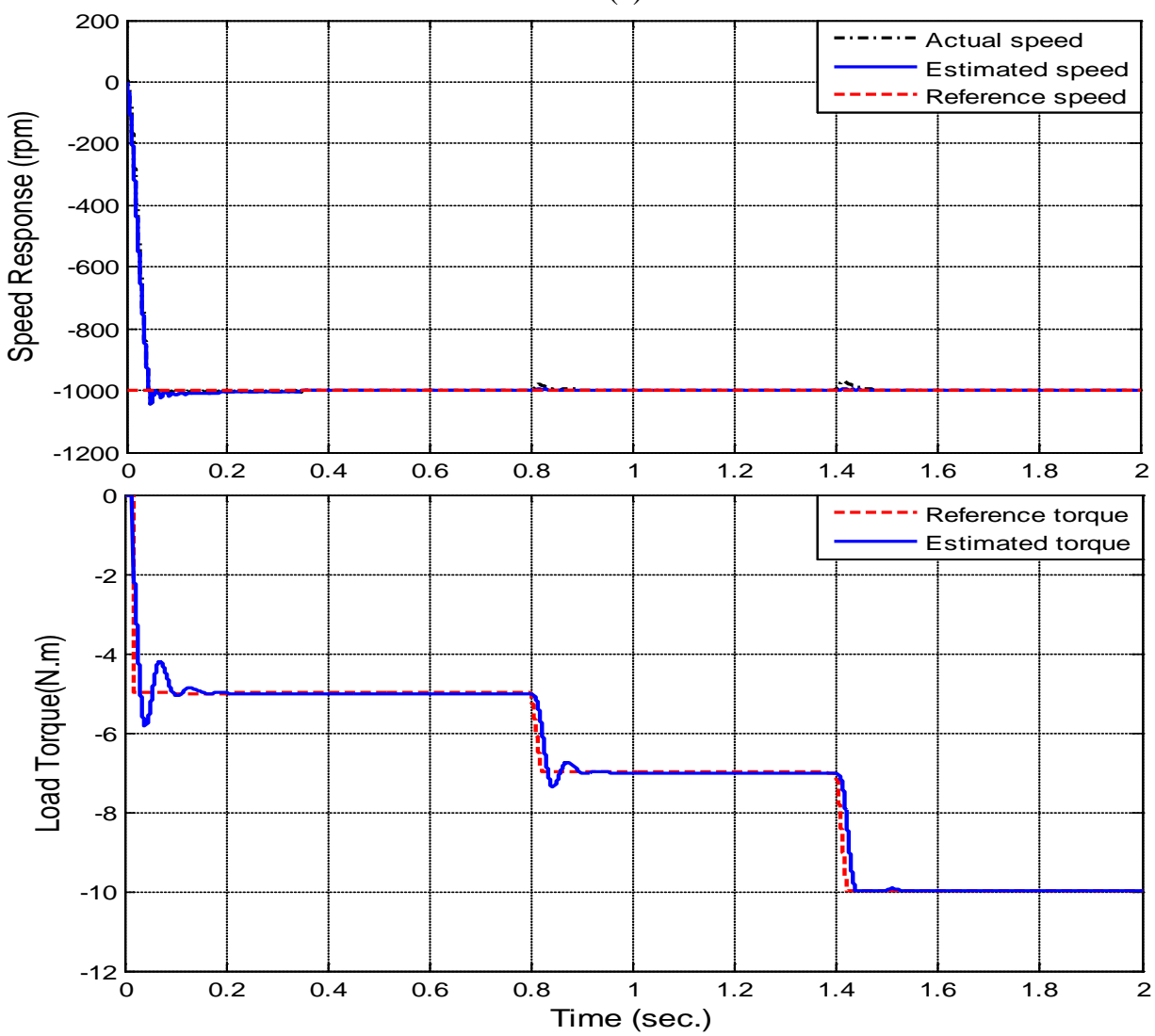

(b)

Figure 8: Speed and torque responses of the DC machine at different load torque values in the (a) forward and (b) reverse motoring modes. 


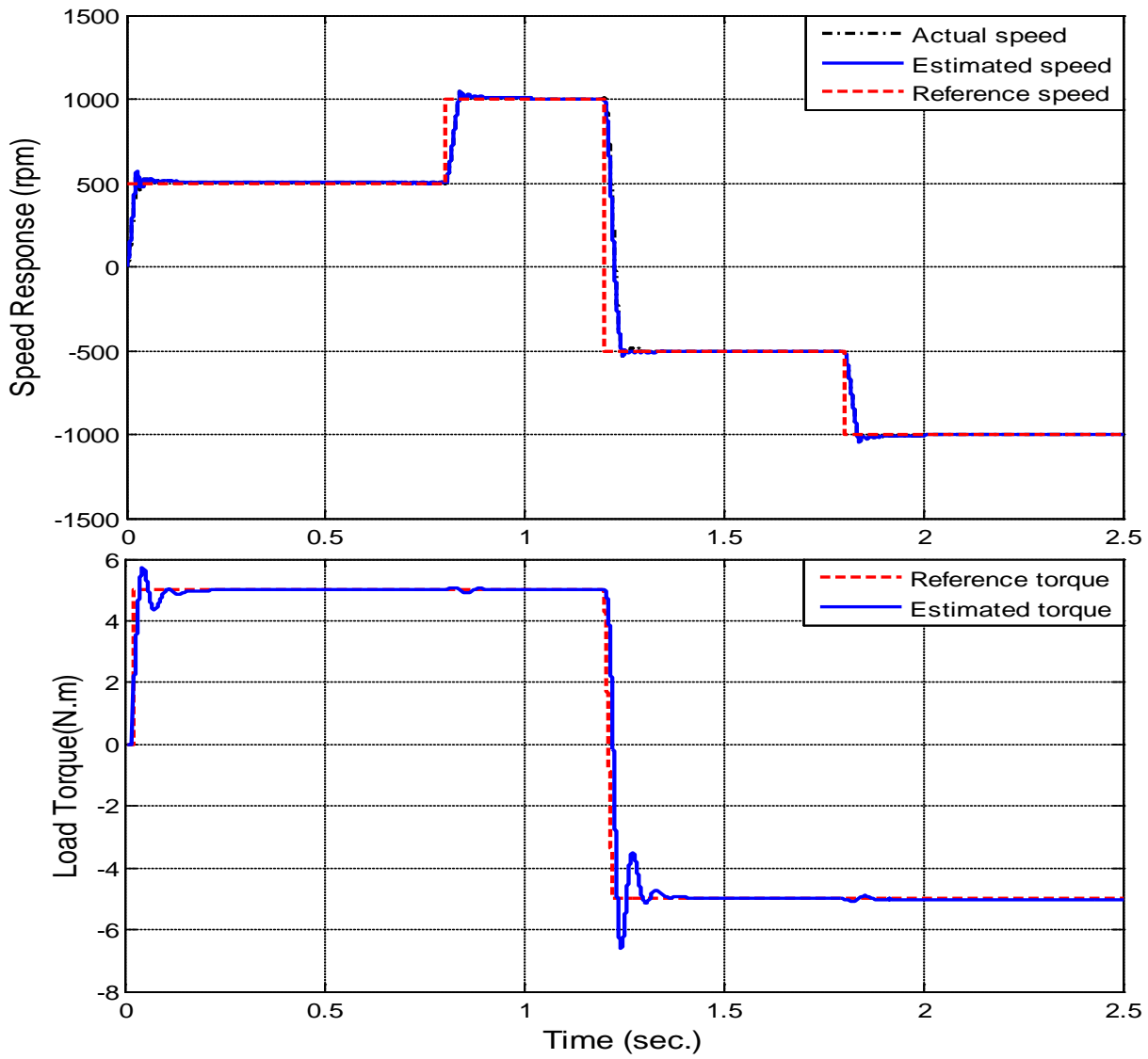

Figure 9: Speed and torque responses of the DC machine during changing in the forward and reverse motoring modes

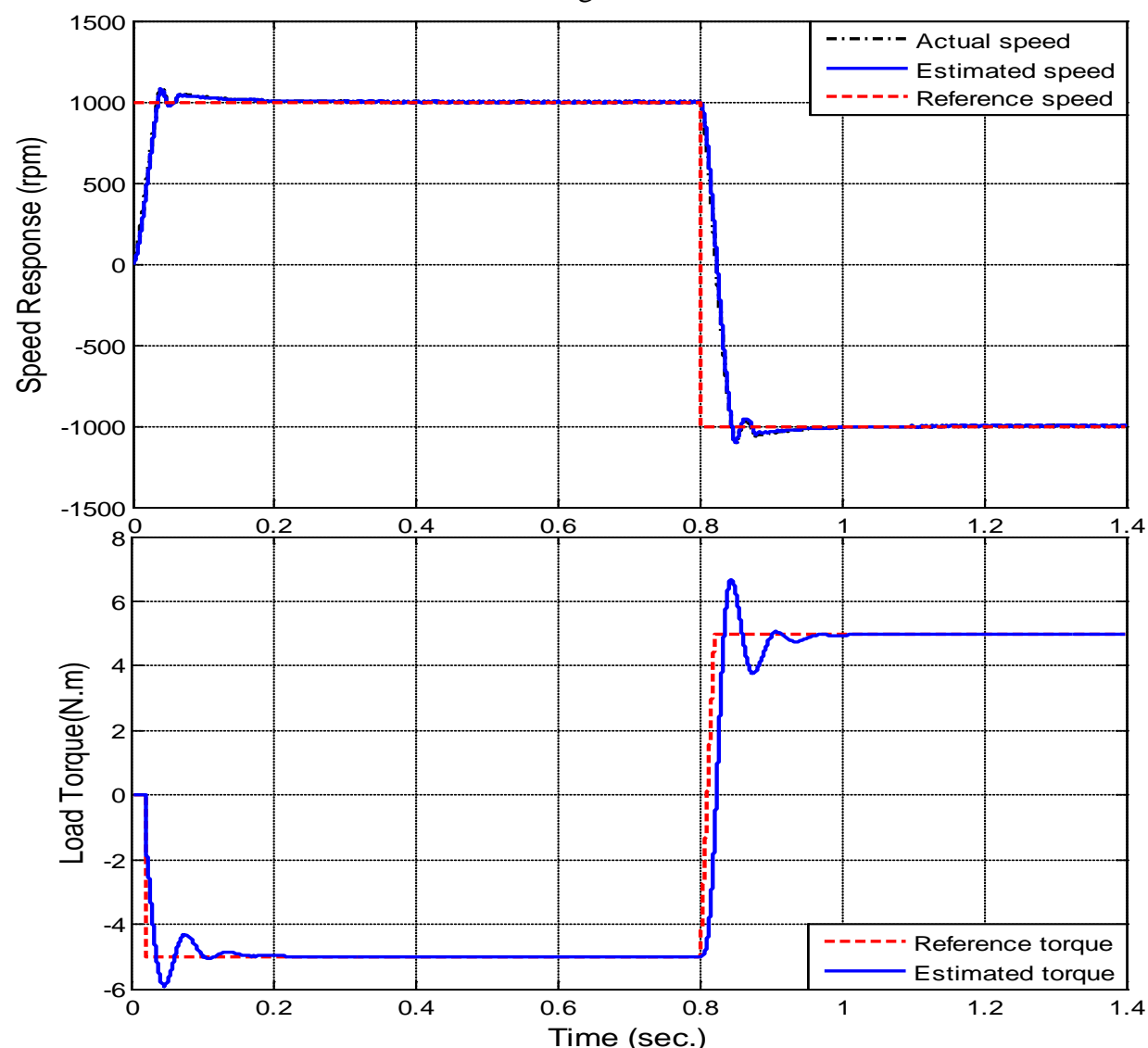

Figure 10: Speed and torque responses of the DC machine during changing in the forward and reverse regenerative modes 


\section{Conclusions}

Sensorless (estimation) speed and torque control of the DC machine in four quadrant operation modes under different speed and load torque conditions has been presented in this paper. Estimation speed and torque based on transfer function characteristics of the DC motor has been done depending on instantaneous average output voltage and current of the DC chopper drive circuit. Simulation results demonstrated that the designed controller is able to estimate machine speed and torque under different operation modes. The estimated speed and torque has high-quality responses during speed and load torque variations. Also the control circuit is simple with low complexity and produces low errors. The limitation of estimation circuit using transfer function characteristics of DC machines is the parameters of the DC machine. This limitation has been solved by using different PI controllers.

\section{References}

[1] M.M. Sankar and G.Sailaja, "Four Quadrant Chopper Control of DC Motor using AT89S52 Microcontroller”, National Conference on Electrical sciences (NCES), pages: 161-165, 2012.

[2] S.R. Khuntia, K.B. Mohanty, S. Panda and C. Ardil, "A Comparative Study of P-I, I-P, Fuzzy and Neuro-Fuzzy Controllers for Speed Control of DC Motor Drive”, International Journal of Electrical and Computer Engineering, pages:287-291, 2010.

[3] G. Y. Mustafa, A. T. Ali, E. Bashier and M. F. Elrahman, “ Neuro-Fuzzy Controller Design for a DC Motor Drive”, University of Khartoum Engineering Journal (UofKEJ), Vol. 3, Issue 1, pages:7-11, February 2013.

[4] Rakan Kh. Antar, Ahmed A. Allu, Ahmed J. Ali, "Sensorless Speed Control of
Separately Excited DC Motor Using Neuro-Fuzzy Controller”, First International Conference of Electrical, Communication, Computer, Power and Control Engineering ICECCPCE'13, IEEE2013, pages: 37-41, December 2013. Mosul, Iraq.

[5] Ahmed A. Allu and Rakan Kh. Antar, "Design and Modeling of Speed Sensorless Control of DC Motor Drive System”, AlRafidain Engineering Journal, University of Mosul, College of Engineering, Vol. 22, No. 5, pages: 89-100, 2014.

[6] Rakan Kh. Antar, Ahmed A. Allu, "Sensorless Speed/Torque Control of DC Machine Using Artificial Neural Network Technique”, Tikrit Journal of Engineering Sciences, Vol.23, No.3, pages: 55-62, 2016.

[7] Mohammad H. Rashid, "Power Electronics: Circuit, Devices and Applications", New Delhi Prentice-Hall of India Private Limited, 1994.

Appendix:

Separately Excited DC machine

specifications [5]:

Voltage Sources $\left(V_{d c} \& V_{f}\right)=220 \mathrm{~V}$,

Armature current $\left(I_{a}\right)=10 \mathrm{~A}$,

Electrical power $=2 \mathrm{~kW}$, Rate Speed $=1400 \mathrm{rpm}$,

Moment of inertia $(J)=0.012 \mathrm{~kg} \cdot \mathrm{m}^{2}$,

Friction coefficient $(B)=0.0204$ N.m.s,

Armature resistance $\left(R_{a}\right)=5 \Omega$,

Armature inductance $\left(L_{a}\right)=60 \mathrm{mH}$,

Field resistance $\left(R_{f}\right)=250 \Omega$,

Field inductance $\left(L_{f}\right)=50 \mathrm{H}$,

Mutual inductance $\left(L_{a f}\right)=1.6 \mathrm{H}$.

\section{MOSFET Specifications:}

ON resistance $\left(\mathrm{R}_{\mathrm{ON}}\right)=0.1 \Omega$,

Internal diode resistance $\left(\mathrm{R}_{\mathrm{d}}\right)=0.01 \Omega$,

Internal diode forward voltage $\left(\mathrm{V}_{\mathrm{f}}\right)=0.7 \mathrm{~V}$,

Snubber resistance and capacitance $=1 \mathrm{k} \Omega$ and $1 \mu \mathrm{F}$

\section{تخمين وسيطرة على سرعة وعزم ماكنة تيار مستمر في حالات التشغيل الاربعة}

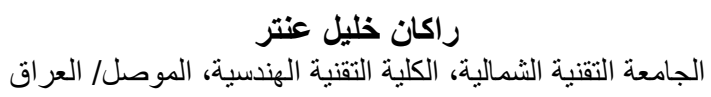

الخلاصة

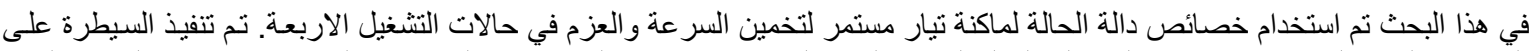

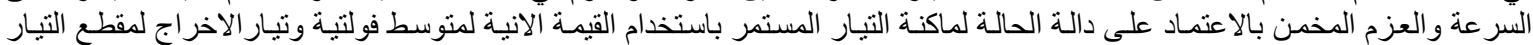

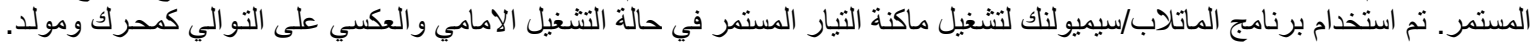

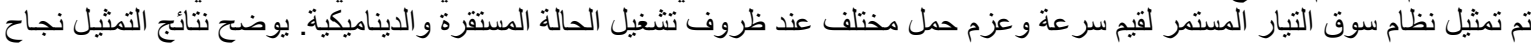
دائرة السيطرة المقترحة و الذي يعطي تو افق واضح بين قيم السر عة و العزم المخمن و الحقيقي والمرجعي. 